Check for updates

Cite this: RSC Adv., 2018, 8, 24250

\title{
Development on porous particles of Pueraria lobatae Radix for improving its compactibility and dissolution
}

\begin{abstract}
MiaoMiao Zhou, ${ }^{\mathrm{ab}}$ YouJie Wang, (DD ${ }^{\mathrm{b}}$ Fei Wu, ${ }^{* a b}$ Lan Shen, $^{\mathrm{a}}$ Xiao Lin (D) *a and Yi Feng ${ }^{\mathrm{b}}$
Herein, we report a study on the influence of particles having different porosities on tablet performance. The ethanol extract of Pueraria lobatae Radix (EPL) was chosen as the model drug. A series of porous EPL particles were prepared by co-spray drying EPL with different amounts of ammonium bicarbonate $\left(\mathrm{NH}_{4} \mathrm{HCO}_{3}\right)$, and their powder properties (particle morphology, particle size, porosity, flowability, bulk density, and tap density) and tablet properties (tensile strength, $E_{\mathrm{sp}}$, yield pressure, dissolution, etc.) were comparatively investigated. The results showed that there were significant differences in the fundamental and functional properties of the spray-dried and parent EPLs. First, the irregular and dense primary EPL particles were transformed into loose, hollow, and spheroidal particles via co-spray drying with $\mathrm{NH}_{4} \mathrm{HCO}_{3}$. Second, compared to parent EPL, porous EPLs showed a significant improvement (1.80-7.03 times) in compactibility. Third, the dissolution rates of porous EPLs were similar, and all were more than twice as fast as that of parent EPL. The increased porosity, on the one hand, led to the increase in interparticle and intraparticle bonding forces during tableting and, on the other hand, facilitated water intrusion into tablets for disintegration and dissolution. Porous particle design is therefore promising, especially for drugs with both poor compactibility and dissolution.
\end{abstract}

Received 15th May 2018

Accepted 21st June 2018

DOI: $10.1039 / c 8 r a 04125 c$

rsc.li/rsc-advances behavior. Moreover, a high dose of excipient(s) due to the inefficiency could be an unacceptable burden for high drugloading tablets like most traditional Chinese medicine (TCM) tablets. Therefore, new strategies, which are different from the simple physical addition of one or more excipients, need to be developed to either effectively resolve multiple problems concurrently or resolve one problem without causing a new one.

In this regard, the development of co-processed drug-based composite particles (CPs) shows some promising results. ${ }^{6,7}$ For example, core-shell CPs, with a small amount of plastic, low hygroscopicity, and low viscosity-grade binder as the shell layer, could effectively address the multiple problems (poor compactibility, poor flowability, and high hygroscopicity) of core materials simultaneously without causing unacceptable influences on tablet disintegration. ${ }^{8-12}$ In this study, some positive results were also achieved by using the porous particle design to effectively address the poor compactibility and slow drug dissolution of a problematic TCM extract.

Porous particles (PPs) are excellent materials, in terms of their high porosity and high specific surface area, which are widely used in the pharmaceutical field. ${ }^{13}$ For example, they can improve the compactibility of tablet formulations, ${ }^{14}$ increase the dissolution rate of APIs, ${ }^{15}$ can be used as carriers to deliver drugs,${ }^{16}$ and so on.${ }^{17}$ There are many methods for preparation of PPs, but the widely used method is to co-process the material with a porogen such as ammonium bicarbonate $\left(\mathrm{NH}_{4} \mathrm{HCO}_{3}\right)$, camphor, menthol and thymol..$^{18-20}$ The porogen would be volatilized using technology to form pores after the material 
and porogen were mixed uniformly. Previous studies have shown that the tablets prepared using porous mannitol showed both improved hardness and shortened disintegration time, compared to those made by parent mannitol, which verified the advantages of PPs. ${ }^{21}$

The preparation of PPs by co-processing includes the vacuum drying method and the spray drying method..$^{21,22}$ In contrast, spray drying constitutes a one-step continuous process to concentrate and dry materials, which reduces the operation steps and thus reduces the costs and enhances the product efficacy. Moreover, the prepared powders are usually porous, sub-globular, and homogeneous with improved physicomechanical properties. ${ }^{10}$ These characteristics altogether provide obvious advantages for the production of PPs via spray drying. Particle engineering based on spray drying may provide a way for improving the internal porosity and functional properties of materials by controlling particle characteristics using volatile porogens. ${ }^{23}$ It was reported that above $50{ }^{\circ} \mathrm{C}, \mathrm{NH}_{4} \mathrm{HCO}_{3}$ could be gasified and converted into $\mathrm{H}_{2} \mathrm{O} \uparrow$, $\mathrm{NH}_{3} \uparrow, \mathrm{CO}_{2} \uparrow ;^{24}$ i.e., it can be directly and totally removed by the heat produced during spray drying, leaving voids within the material, thus significantly increasing its porosity. ${ }^{21}$

Although PPs have gradually infiltrated the field of pharmaceutics, we have not yet seen any related reports about TCMbased PPs. The ethanol extract of Pueraria lobatae Radix (EPL), which is commonly used in clinics for the treatment of deafness, diarrhea, acute dysentery, and cardiovascular diseases, ${ }^{25}$ is a kind of TCM powder with poor compactibility and slow dissolution rate. Based on the above background, we aimed to develop porous EPL by co-spray drying EPL with different amounts of $\mathrm{NH}_{4} \mathrm{HCO}_{3}$ for simultaneously solving its tableting and dissolution problems. Moreover, we also integrated information from the particle level (particle shape and surface structure, particle size and distribution, porosity) and the powder level (flowability, bulk density, tap density, compressibility, and compactibility) to clarify the mechanism of the improved properties of porous EPL.

\section{Experimental}

\subsection{Materials}

The ethanol extract of Pueraria lobatae Radix (EPL, Hanzhong Trg Biotech Co., Ltd., Shanxi, China), and ammonium bicarbonate $\left(\mathrm{NH}_{4} \mathrm{HCO}_{3}, \quad\right.$ SinopharmChemical Reagent Co., Shanghai, China) were used as supplied.

\subsection{Preparation of spray dried porous EPLS}

EPL $(12 \% \mathrm{w} / \mathrm{w})$ and a certain amount of ammonium bicarbonate $\left(\mathrm{NH}_{4} \mathrm{HCO}_{3}\right)(0-1.6 \%)$ were dissolved in distilled water. The solution was then spray dried using a laboratory-scale spray dryer (Mini Spray Dryer B-290, Buchi Labortechnik AG, Switzerland) equipped with a $1.5 \mathrm{~mm}$ nozzle. The preparation conditions were as follows: inlet temperature, $130{ }^{\circ} \mathrm{C}$; aspirator rate, $100 \%$; pump, $30 \%$; feed rate, $40 \%$. The process yield (\%) was calculated after each run using eqn (1):

$$
\text { Yield }(\%)=\frac{m_{0}}{m_{1}} \times 100
$$

where $m_{0}$ represents the mass of the spray-dried product and $m_{1}$ represents the mass of solids in the feed solution.

\subsection{Material characterization}

2.3.1. Moisture content. The moisture content of materials was tested by a fast infrared moisture analyzer (MA35M, Sartorius Ltd, Germany). About $2 \mathrm{~g}$ of sample was put into the instrument, followed by drying at $105{ }^{\circ} \mathrm{C}$; the results were recorded until a constant reading was achieved.

2.3.2. True density. The true density $\left(\rho_{\mathrm{t}}\right)$ was measured using a helium pycnometer from Micromeritics Instruments Ltd. (AccuPyc 1340, U.S.A). Each sample was put into a sample cell and the true volume of each sample was assessed and, in turn, the true density was assessed.

2.3.3. Density and flowability. The density and flowability were determined using a powder property tester (Baite Corporation, China). The powder was added to a $100 \mathrm{~cm}^{3}$ measuring cylinder with weight $m_{2}$ through a vibrating metal funnel. The excess powder was scraped off when the powder completely filled the cylinder. The weight of the cylinder and powder was recorded as $m_{3}$. The bulk density $\left(\rho_{\mathrm{b}}\right)$ was calculated using eqn (2):

$$
\rho_{\mathrm{b}}=\frac{m_{3}-m_{2}}{100}
$$

More powder was added to the cylinder after it was combined with a glass sleeve, then it was tapped for $6 \mathrm{~min}$. The weight of the cylinder and powder was recorded again as $m_{4}$ after the excess powder was scraped off. The tap density $\left(\rho_{\text {ta }}\right)$ was calculated using eqn (3):

$$
\rho_{\mathrm{ta}}=\frac{m_{4}-m_{2}}{100}
$$

The Hausner ratio (HR) and Carr index (CI), representing the compressibility and flowability of powders, respectively, were calculated using eqn (4) and (5):

$$
\begin{gathered}
\mathrm{HR}=\frac{\rho_{\mathrm{ta}}}{\rho_{\mathrm{b}}} \\
\mathrm{CI}=\frac{\rho_{\mathrm{ta}}-\rho_{\mathrm{b}}}{\rho_{\mathrm{ta}}} \times 100
\end{gathered}
$$

The angle of repose, which also represents the flowability of materials, was also measured by the powder property tester. The powder was poured onto a platform through a vibrating funnel until a height-fixed and stable heap was formed. The angle between the horizontal and the heap was recorded as the angle of repose.

2.3.4. Porosity. The porosity of the powder was calculated using eqn (6):

$$
\varepsilon=1-\frac{\rho_{\mathrm{b}}}{\rho_{\mathrm{t}}}
$$

2.3.5. Particle size analysis. Particle size was measured using laser diffraction (Malvern 2000, Malvern Instruments Ltd, 
England). The median particle size $\left(D_{0.5}\right)$ was measured automatically and the span, which represents the particle size distribution, was calculated as follows:

$$
\text { Span }=\frac{D_{0.9}-D_{0.1}}{D_{0.5}}
$$

2.3.6. Morphology. The morphology of the powder was observed under a scanning electron microscope (S-3400, Hitachi Ltd, Japan) at an acceleration voltage of $10 \mathrm{kV}$. Samples were observed at different magnifications after they were sputter coated (E-1010, Hitachi Ltd, Japan) with gold-palladium.

2.3.7. Powder X-ray diffraction (XRD). The samples were determined using an X-ray diffractometer (D8 Advance, A25, Bruker Ltd., Germany) with the radiation condition of $40 \mathrm{kV}$ and $40 \mathrm{~mA}$. The angular range $(2 \theta)$ was $3-50^{\circ}$ and the measurement speed was $5^{\circ} \min ^{-1}$.

2.3.8. Compactibility. Tablets were prepared by a fully instrumented press (Korsch XP1, Germany) with $8.5 \mathrm{~mm}$, round, and flat-faced punches at different compaction forces $(2.0,4.5$, or $7.0 \mathrm{kN})$, and the compaction speed was 10 tablets per min. For each sample, the thickness $(T, \mathrm{~mm})$, diameter $(D$, $\mathrm{mm})$, and hardness $(F, \mathrm{~N})$ of five tablets at each compaction force were tested immediately by a hardness tester (Sotax HT10, Switzerland). The tensile strength (TS) of the tablets was calculated using eqn (8): ${ }^{26}$

$$
\mathrm{TS}=\frac{2 F}{\pi D T}
$$

The work was also calculated for each tablet during compaction. The $E_{\mathrm{sp}}$ value was calculated using eqn (9):

$$
E_{\mathrm{sp}}=\frac{E_{2}}{W}
$$

where $E_{2}$ presents the effective compaction work (J) and $W$ is the tablet weight $(\mathrm{g})$.

2.3.9. Heckel profile analysis. The "in-die" method was used and the compaction was performed as described above. The Athy-Heckel eqn (10) was used to investigate the volume reduction mechanism during compaction:

$$
\ln \frac{1}{1-D}=k P+A
$$

where $D$ is the relative density of compacts at the pressure $P$; $k$ is a material constant, which is the slope of the linear portion of the Heckel plot. $P_{\mathrm{y}}$, which is the reciprocal of $k$, represents the plastic deformability of samples under pressure.

2.3.10. Fast elastic stretch (FES). FES, representing the axial elastic recovery of a tablet in a die, was calculated using eqn $(11):^{27}$

$$
\operatorname{FES}(\%)=\frac{T_{1}-T_{2}}{T_{2}} \times 100
$$

where $T_{1}$ and $T_{2}$ represent the edge thicknesses of the tablet during unloading and at the maximum compaction force, respectively.
2.3.11. Tablet dissolution. The dissolution tests were carried out using a RC8MD Dissolution Tester (Tian Da Tian Fa Science and Technology Ltd, China). The basket-stirring method was used. Distilled water $(900 \mathrm{~mL})$ was used as the dissolution medium at a temperature of $37 \pm 0.5{ }^{\circ} \mathrm{C}$ and the speed was $100 \mathrm{rpm}$. For each tablet, the dissolution tests were performed in triplicate. Samples $(5 \mathrm{~mL})$ were taken and replaced with fresh dissolution medium immediately at 5, 15, 30, 45, and $60 \mathrm{~min}$. The samples were filtered through a $0.45 \mu \mathrm{m}$ filter and analyzed spectrophotometrically at $250 \mathrm{~nm}$ using HPLC (Agilent 1260, Agilent Corporation, USA). The analytical column was a Waters Symmetry C18 $(4.6 \times 250 \mathrm{~mm}, 5 \mu \mathrm{m})$ and the column temperature was $30{ }^{\circ} \mathrm{C}$. The injection volume was $10 \mu \mathrm{L}$ and the flow rate was $1.0 \mathrm{~mL} \mathrm{~min}^{-1}$. The mobile phase was a gradient solvent system which composed of methanol (A) and $0.05 \%$ phosphoric acid aqueous solution (B): 0-10 min: linear 25-30\% A; 10-20 min: isocratic 30\% A; 20-40 min: linear 30-70\% A; 4045 min: linear $70-25 \% \mathrm{~A}$; 45-50 min: isocratic $25 \% \mathrm{~A}$.

The similarity factor $\left(f_{2}\right)$ of dissolution profiles was calculated using eqn (12):

$$
f_{2}=50 \log \left\{\left[1+\frac{1}{n} \sum_{t=1}^{n}\left(R_{t}-T_{t}\right)^{2}\right]^{-0.5} \times 100\right\}
$$

where $n$ is the number of time points, $R_{t}$ is the dissolution value of the reference product at time $t$, and $T_{t}$ is the dissolution value of the test product at time $t$. Only one time point above $85 \%$ drug release was used in the calculation. The $f_{2}$ value $(0-50)$ is taken as the criterion for inequivalence.

\section{Results and discussion}

In this work, porous EPLs were prepared via spray drying with $\mathrm{NH}_{4} \mathrm{HCO}_{3}$ as the porogen. In general, the methods for preparing PPs are as follows: (i) the use of porogens or templating agents; ${ }^{28,29}$ (ii) the formation of holes by the matrix of particles, which only applies to amphiphilic polymers; ${ }^{30}$ (iii) chemical synthesis, which is usually suitable for preparing Sirelated PPs. ${ }^{31}$ The applicability of the latter two methods is too narrow for fabricating porous APIs. In contrast, using porogens or templating agents could meet the needs of our study. In an application, porogens or templating agents are first mixed with materials uniformly and then removed using a specific method. In this respect, porogens show some advantages since they could directly sublime during spray drying, while templating agents require the use of a large amount of organic solvent to wash off them. ${ }^{13}$ It is therefore preferable to use porogens for forming pores, considering their simplicity, safety, and economy. There are many porogens, such as $\mathrm{NH}_{4} \mathrm{HCO}_{3}$, camphor, menthol, and thymol, most of which are insoluble in water, with the exception of $\mathrm{NH}_{4} \mathrm{HCO}_{3}$, which can directly gasify above $50{ }^{\circ} \mathrm{C}$; these properties of $\mathrm{NH}_{4} \mathrm{HCO}_{3}$ make it very suitable for this study.

\subsection{Morphology and powder properties}

The morphologies of the particles are shown using SEM in Fig. 1. It can be clearly seen that the morphology of spray dried 
(1)
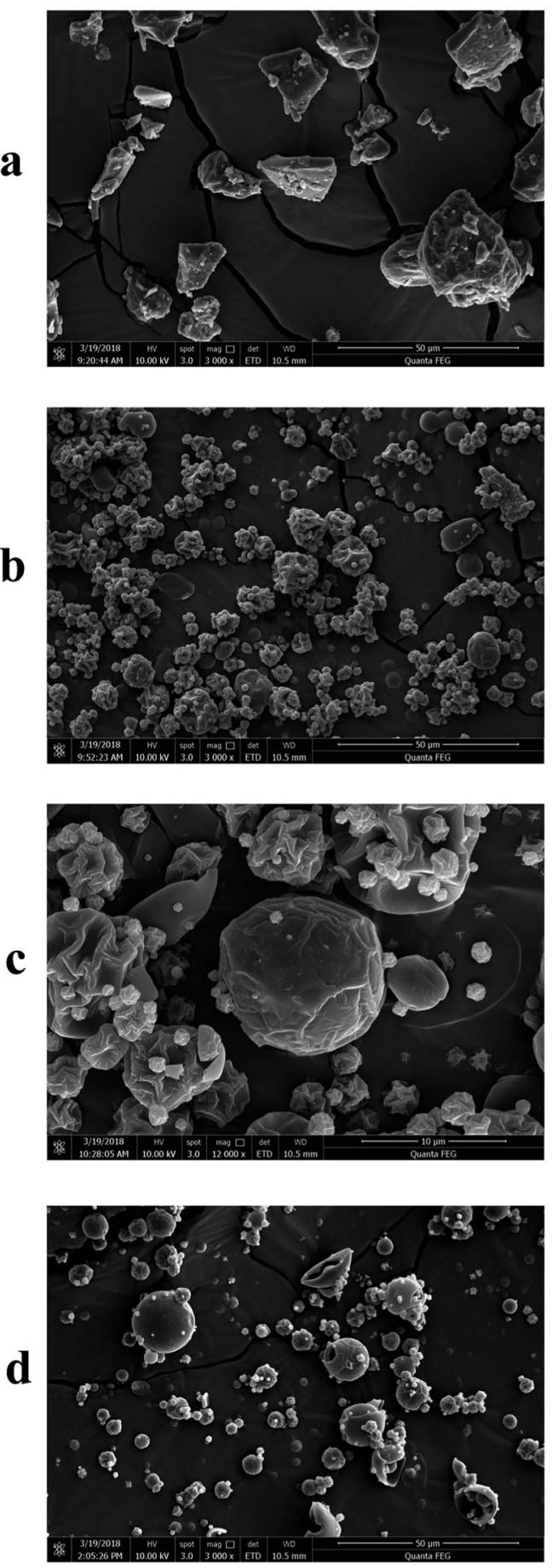

(2)
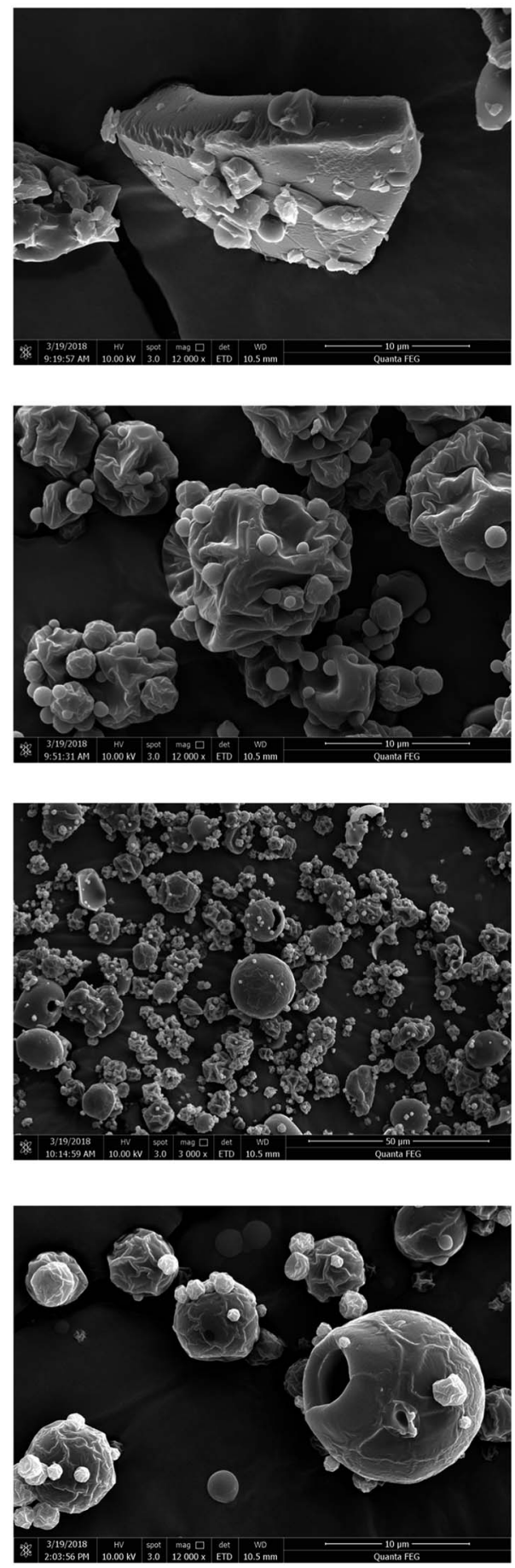

Fig. 1 Scanning electron photomicrographs of EPL particles. (a) Parent EPL; (b) EPL spray dried without $\mathrm{NH}_{4} \mathrm{HCO}_{3}$; (c) EPL spray dried with 6.67\% $\mathrm{NH}_{4} \mathrm{HCO}_{3}$; (d) EPL spray dried with 13.33\% $\mathrm{NH}_{4} \mathrm{HCO}_{3}$. ((1) Magnification: $3000 \times$; (2) magnification: 12 000 x; EPL, the ethanol extract of Pueraria lobatae Radix).

secondary particles (Fig. 1b-d) was significantly different from that of the primary particles (Fig. 1a); the irregular and dense primary EPL particles were transformed into loose, hollow, and spheroidal ones via spray drying. The spherification degree of the particles was gradually increased with the amount of $\mathrm{NH}_{4} \mathrm{HCO}_{3}$ in the feed. However, when the EPL-containing feed was spray dried without the addition of $\mathrm{NH}_{4} \mathrm{HCO}_{3}$, the resulting secondary particles generally had quite plicated surfaces. These results can be explained using the Peclet number (Pe) concept, $\mathrm{Pe}=k / 8 D .^{23}$ The $k$ represents the droplet evaporation rate and the $D$ is the diffusion coefficient of the solute. Because of the heat-mass transfer between the surrounding warm air and the 


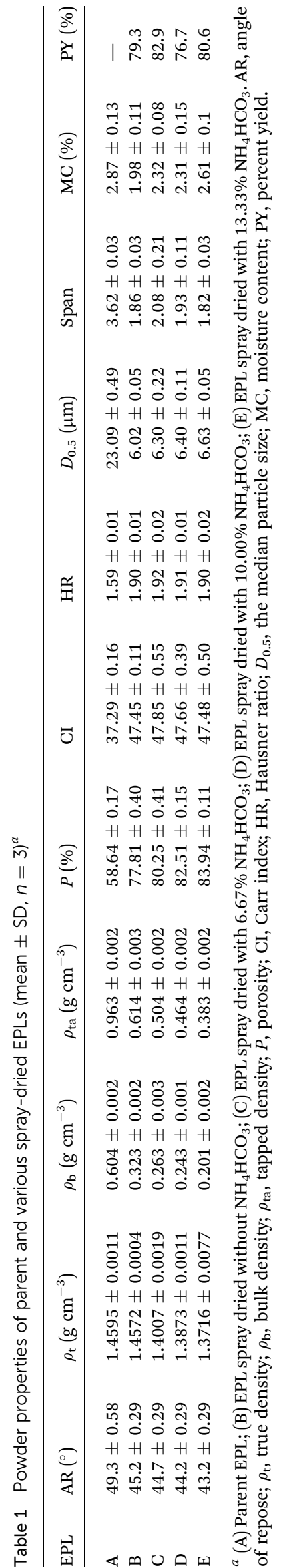

drying droplet, the solute can precipitate on the surface of droplets followed by forming a shell when the diffusivity of the solute particles $(D)$ (from outside to inside of the droplet) is lower than the evaporation rate $(k)$ of the solvent (from inside to outside of the droplet). ${ }^{21}$ Therefore, a hollow particle is generated with the solvent in the center of the droplet being continuously evaporated. Coincident with the above theoretical analysis, it has been reported that pharmaceutical particles prepared by spray drying have a tendency to be hollow because the evaporation of the solvent is generally a thousand-fold faster than the diffusivity of the solute; ${ }^{32}$ i.e., spray drying itself seems to produce hollow particles with cupped surfaces. In addition, it was also observed in this study that adding a small amount of $\mathrm{NH}_{4} \mathrm{HCO}_{3}$ to the feed could significantly reduce the occurrence of cupped surfaces and make the spray dried particles more spherical and the particle surface smoother. This may be because $\mathrm{NH}_{4} \mathrm{HCO}_{3}$ in the center of droplets is rapidly transferred into gas during spray drying and continuous evaporation, further speeding up the evaporation rate of the solvent and resulting in a higher pressure in the droplet. This was also indicated by some surface holes in these particles, which could be caused by the eruptive release of internal high pressures of drying particles. As a result, the porosity of particles increased with the level of $\mathrm{NH}_{4} \mathrm{HCO}_{3}$ in the feed (Table 1).

Both the surface and the transverse sections of various EPL tablets were also observed using SEM (Fig. 2). Parent EPL tablets were generally composed of many irregular particles, which still seemed inter-independent under pressure (Fig. 2a). Since the parent EPL particles were quite dense (Fig. 1a), the contact between them was limited to a relatively small surface area during compacting. This resulted in more interparticle gaps and thus, more loose tablets. However, the spray-dried EPL tablets showed a clearly different morphology from that of parent EPL tablets. On the one hand, the tablets became very tight and dense (Fig. 2b-d). Because of the spheroidal and porous/hollow structure, these spray-dried particles were easily broken under pressure, which increased the interparticle and intraparticle contact areas and thus, led to a tight combination. This phenomenon was more and more obvious with the increasing the use level of $\mathrm{NH}_{4} \mathrm{HCO}_{3}$ due to increased porosity. On the other hand, the spray-dried EPL tablets showed more even and higher porosity than the parent EPL tablets (Fig. 2(3) and (4)). This is because of the more even particle shape and size distribution of spray-dried particles and the porous and/or hollow nature of each such particle, respectively.

The XRD results showed that the parent EPL mainly existed in an amorphous state, which was sustained after spray drying (Fig. 3). Since the powder properties of materials might be significantly affected by the moisture content, all the materials studied were dried under the same conditions to obtain low and similar moisture contents before characterization. The results are summarized in Table 1 . The data showed that the particle sizes of spray-dried EPL were markedly smaller than that of parent EPL, which could also be clearly observed under the same magnification of the electron micrographs (Fig. 1). This was caused by the small nozzle orifice of the mini spray dryer used. Generally, a too small particle size will lead to poor 
(1)
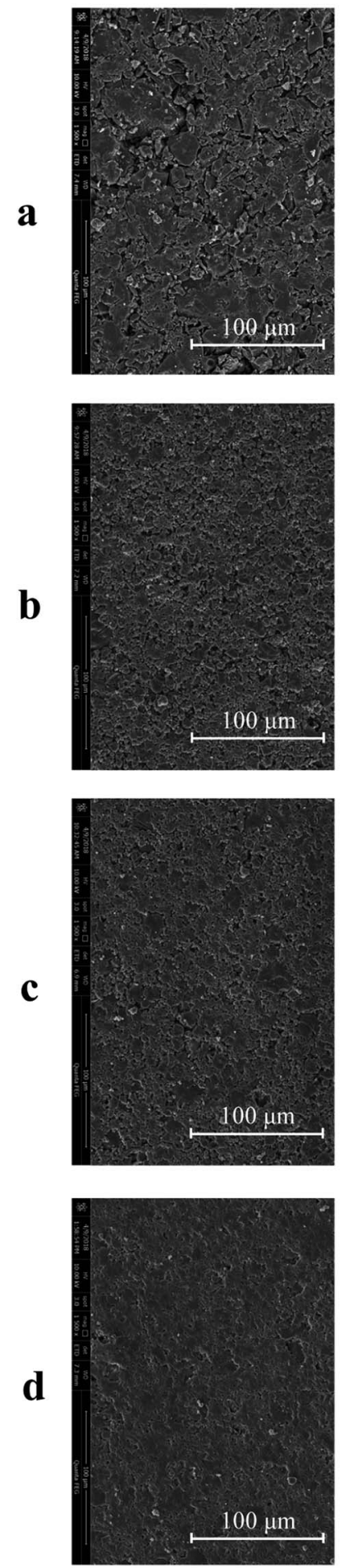

(2)
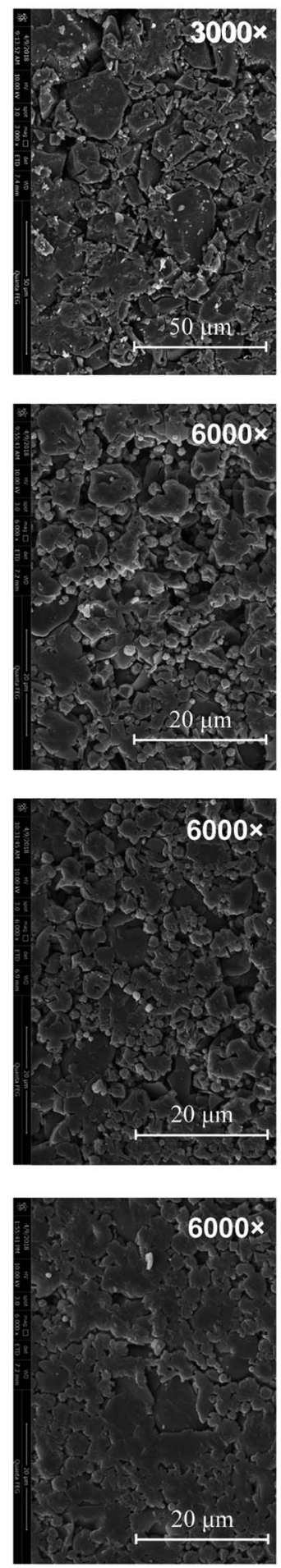

(3)
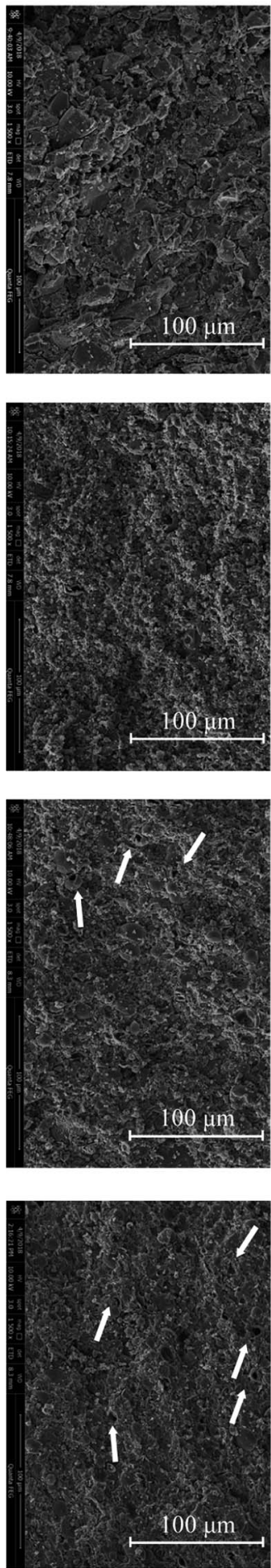

(4)
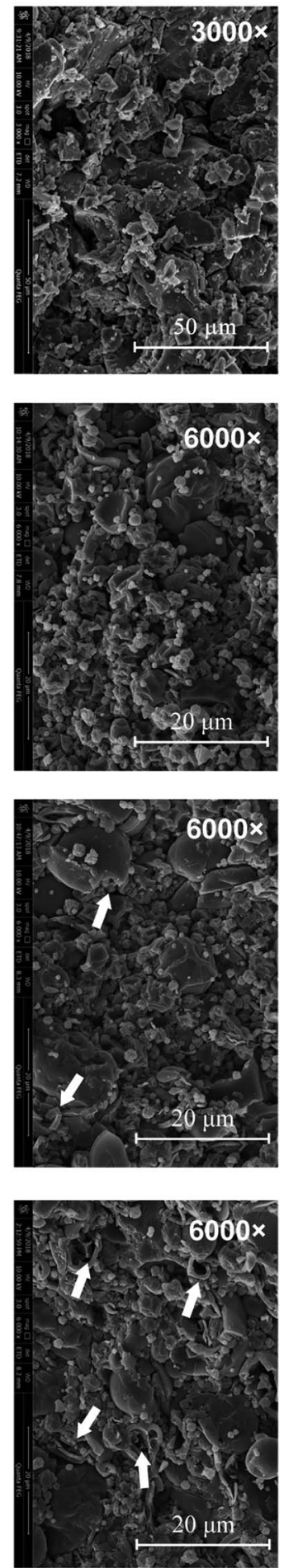

Fig. 2 Scanning electron photomicrographs of EPL tablets (under the compaction force of $4.5 \mathrm{kN}$ ). (a) Parent EPL; (b) EPL spray dried without $\mathrm{NH}_{4} \mathrm{HCO}_{3}$; (c) EPL spray dried with $6.67 \% \mathrm{NH}_{4} \mathrm{HCO}_{3}$; (d) EPL spray dried with $13.33 \% \mathrm{NH}_{4} \mathrm{HCO}_{3}$. ((1) and (2) The surface of tablets; (3) and (4) the transverse section of tablets; the magnification of (1) and (3): 1500x; EPL, the ethanol extract of Pueraria lobatae Radix; arrows in c(3), c(4), d(3), $d(4)$ point to the broken hollow particles).

flowability. In this study, spray dried EPLs, though having a markedly smaller particle size, showed smaller angles of repose than parent EPL, indicating better flowability behavior. This could mainly be due to their significantly different particle shapes (spherical vs. irregular). Moreover, some fine spray dried particles tended to adsorb on the surface of large ones to form aggregates (Fig. 1) and acted as a glidant, thus improving the flowability to some degree. This might also be due to 


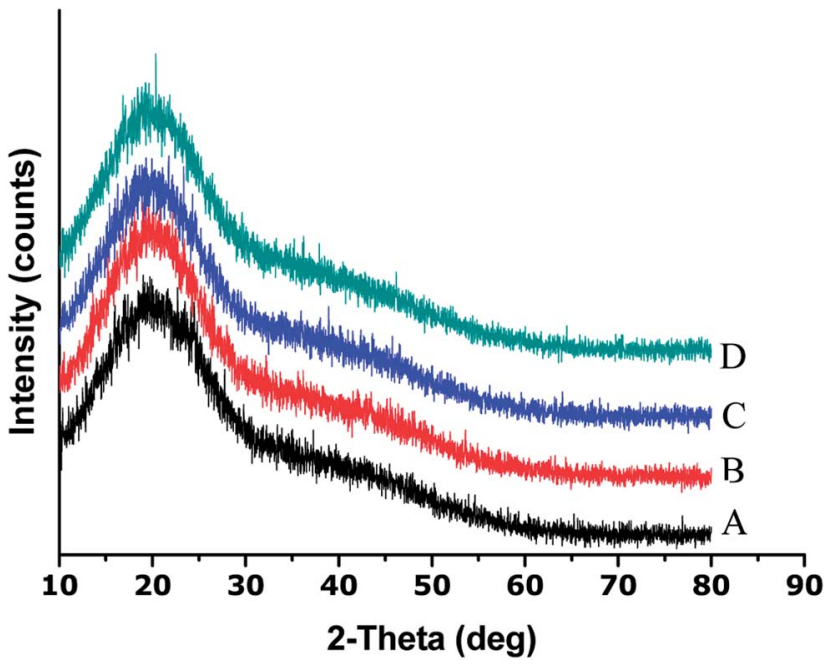

Fig. 3 XRD patterns of parent and spray dried EPLs ((A) Parent EPL; (B) EPL spray dried without $\mathrm{NH}_{4} \mathrm{HCO}_{3}$; (C) EPL spray dried with $6.67 \%$ $\mathrm{NH}_{4} \mathrm{HCO}_{3}$; (D) EPL spray dried with $13.33 \% \mathrm{NH}_{4} \mathrm{HCO}_{3}$ ).

electrostatic interactions among particles; ${ }^{33}$ particles with opposite charge were clustered together and those with like charge repelled each other, thereby reducing the angle of repose. In addition, the flowability of products can definitely be further improved by preparing larger particle size powders using larger-scale spray driers.

\subsection{Tableting properties}

The tensile strength (TS) of tablets can be used to evaluate the compactibility of the tableted feed; the higher the TS, the better the compactibility of the feed. The TS profiles of parent EPL and spray dried EPLs with different amounts of $\mathrm{NH}_{4} \mathrm{HCO}_{3}(0 \%$, $6.67 \%, 10.00 \%$, and $13.33 \%$ ) under compaction force of $2.0-7.0$ kN, shown in Fig. 4. On the whole, the TS for spray-dried EPLs were significantly higher than that for parent EPL and gradually increased with the amount of $\mathrm{NH}_{4} \mathrm{HCO}_{3}$ used. Specifically, EPLs spray dried with $0 \%, 6.67 \%, 10.00 \%$, and $13.33 \% \mathrm{NH}_{4} \mathrm{HCO}_{3}$

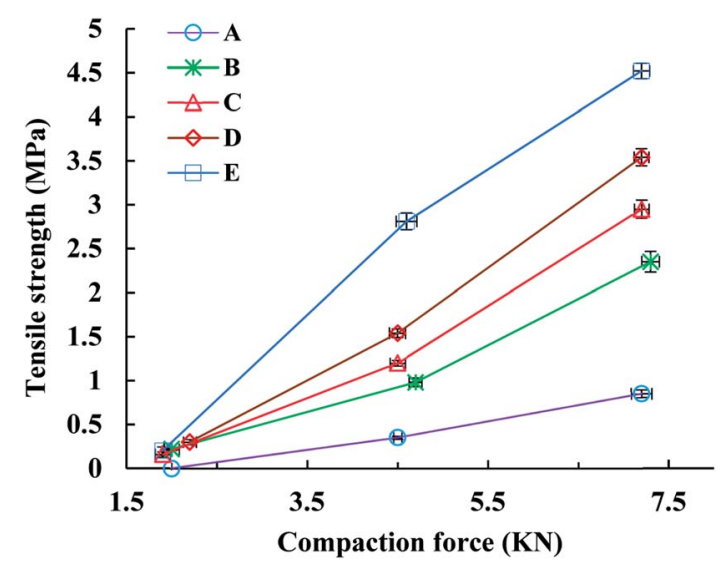

Fig. 4 Tensile strength vs. compaction force profiles for various EPLs. ((A) Parent EPL; (B) EPL spray dried without $\mathrm{NH}_{4} \mathrm{HCO}_{3}$; (C) EPL spray dried with $6.67 \% \mathrm{NH}_{4} \mathrm{HCO}_{3}$; (D) EPL spray dried with $10.00 \% \mathrm{NH}_{4} \mathrm{HCO}_{3}$; (E) EPL spray dried with $13.33 \% \mathrm{NH}_{4} \mathrm{HCO}_{3}$ ) (mean $\left.\pm \mathrm{SD}, n=5\right)$. showed 1.80, 2.43, 3.16-3.40, and 4.32-7.03 times higher tablet TS than parent EPL, respectively. In fact, it seems impossible for parent EPL to produce tablets with the commonly required TS $(\geq 2 \mathrm{MPa}$ ), even under higher compaction pressures. In contrast, the compactibility of spray dried porous EPLs was obviously improved, which could meet the TS requirement under the middle $(\sim 4 \mathrm{kN})$ and/or high $(\sim 7 \mathrm{kN})$ compaction force(s) used in this study. On the other hand, this tendency could also be observed using SEM in Fig. 2, which showed different tightness levels for different EPL tablets. All of these results can be attributed to the increased porosity of the powders. The higher the porosity, the greater the improvement of compactibility. ${ }^{34}$ For EPL spray dried without $\mathrm{NH}_{4} \mathrm{HCO}_{3}$, the improvement was caused by the spray drying process itself, which could make the powder hollow and thus, increase its porosity. ${ }^{32}$ For EPLs spray dried with $\mathrm{NH}_{4} \mathrm{HCO}_{3}$, the evaporation of $\mathrm{NH}_{4} \mathrm{HCO}_{3}$ during spray drying further helped to increase the porosity of the powder due to the reason given in the previous section. During tableting, the particles undergo rearrangement and recombine together under pressure. ${ }^{35}$ On the one hand, the highly porous particles with large surface area increased the contact area between particles. On the other hand, the intraparticle contact points were also increased because of the hollow structure inside the particle. This was confirmed by the data of tablet porosity in Table 2 and Fig. 2. Both interparticle and intraparticle contact points significantly enhanced the bonding forces between and within particles during compaction, causing the particles to bond together firmly and be difficult to segregate. ${ }^{13,36}$ Therefore, as a whole, it was observed in this study that the higher porosity of powders led to the higher TS of tablets.

The $E_{\mathrm{sp}}$ value, a parameter characterizing the retained energy in tablets after unloading, is related to the deformation ability of the feed. In this study, the trend of the $E_{\mathrm{sp}}$ profiles was similar to that of the TS profiles (Fig. 5). Namely, the $E_{\mathrm{sp}}$ values of spray dried EPLs were higher than that of parent EPL under the same compaction force and also increased with the use of $\mathrm{NH}_{4} \mathrm{HCO}_{3}$ during spray drying. A high $E_{\mathrm{sp}}$ value often means that more energy was used to facilitate the irreversible deformation of the tableted material, thus enhancing the hardness of tablets and resulting in larger tablet TS. ${ }^{10}$

Summarized in Table 2 are the tableting parameters of parent and spray-dried EPLs, including compression ratio, yield pressure $\left(P_{\mathrm{y}}\right)$, fast elastic stretch, and porosity loaded and unloaded, which can be applied to analyze the compression and compaction mechanism of these EPLs.

The Athy-Heckel plot describes the change in relative density in a powder column as a function of the applied pressure, and it is commonly used to research the compaction process of a powder ${ }^{37}$ In this study, the $P_{\mathrm{y}}$ and intercept (A) values, which indicate the powder densification mechanism, ${ }^{35,38}$ were obtained from the terminal linear region of all Heckel plots at the compaction pressure range of 20-70 MPa with correlation coefficients being from 0.9991 to 0.9994 . The inverse of the slope $k$, namely $P_{\mathrm{y}}$, reflects the deformability of materials under pressures. As shown in Fig. 5, all of the Heckel profiles are mainly parallel, which means a similar $k$ value for all the 
Table 2 Tableting parameters of parent and various spray-dried EPLs (mean $\pm \mathrm{SD}, n=5)^{a}$

\begin{tabular}{|c|c|c|c|c|c|c|}
\hline EPL & CR (\%) & $P_{\mathrm{y}}^{b}(\mathrm{MPa})$ & FES (\%) & PL & PuL & PL-PuL \\
\hline A & $24.56 \pm 0.09$ & $100.35 \pm 2.56$ & $6.00 \pm 0.66$ & $10.87 \pm 0.55$ & $16.49 \pm 1.27$ & $5.62 \pm 1.26$ \\
\hline B & $24.30 \pm 0.14$ & $121.62 \pm 1.99$ & $6.97 \pm 0.70$ & $21.26 \pm 0.50$ & $26.40 \pm 0.30$ & $5.13 \pm 0.51$ \\
\hline $\mathrm{D}$ & $25.48 \pm 0.04$ & $102.30 \pm 1.39$ & $8.48 \pm 0.30$ & $22.88 \pm 0.33$ & $28.91 \pm 0.38$ & $6.03 \pm 0.20$ \\
\hline $\mathrm{E}$ & $24.47 \pm 0.46$ & $97.32 \pm 1.39$ & $7.86 \pm 0.31$ & $19.60 \pm 0.95$ & $25.46 \pm 0.81$ & $5.86 \pm 0.25$ \\
\hline
\end{tabular}

${ }^{a}$ (A) Parent EPL; (B) EPL spray dried without $\mathrm{NH}_{4} \mathrm{HCO}_{3}$; (C) EPL spray dried with $6.67 \% \mathrm{NH}_{4} \mathrm{HCO}_{3}$; (D) EPL spray dried with $10.00 \% \mathrm{NH}_{4} \mathrm{HCO}$; (E) EPL spray dried with $13.33 \% \mathrm{NH}_{4} \mathrm{HCO}_{3}$. CR, compression ratio; FES, fast elastic stretch; $P_{\mathrm{y}}$, yield pressure; PL, porosity loaded; PuL, porosity unloaded. CR, FES, PL, and PuL were determined under the compaction force of $4.5 \mathrm{kN}$. ${ }^{b}$ The yield pressure was obtained at the compaction pressure range of 20-70 $\mathrm{MPa}$.

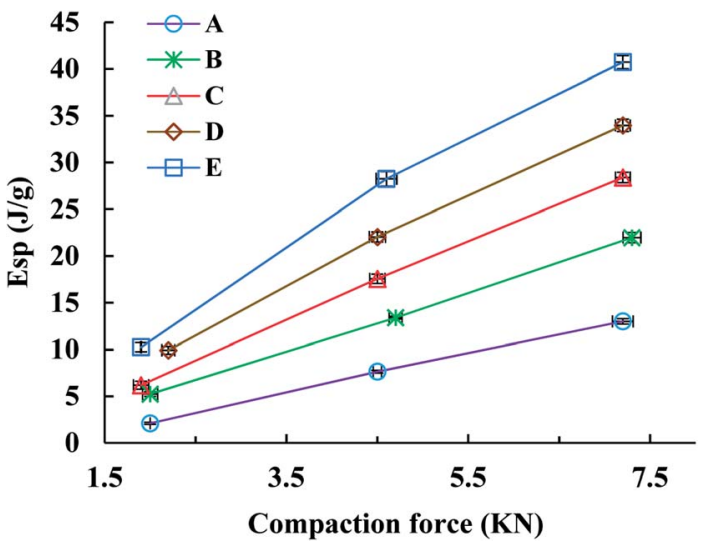

Fig. $5 E_{\text {sp }}$ profiles for various EPLs. ((A) Parent EPL; (B) EPL spray dried without $\mathrm{NH}_{4} \mathrm{HCO}_{3}$; (C) EPL spray dried with $6.67 \% \mathrm{NH}_{4} \mathrm{HCO}_{3}$; (D) EPL spray dried with $10.00 \% \mathrm{NH}_{4} \mathrm{HCO}_{3}$; (E) EPL spray dried with $13.33 \%$ $\mathrm{NH}_{4} \mathrm{HCO}_{3}$ ) (mean $\left.\pm \mathrm{SD}, n=5\right)$.

profiles. Data in Table 2 also showed that there were no significant differences in $P_{\mathrm{y}}$ among parent and spray dried EPLs. Moreover, the parallel plots and low $P_{\mathrm{y}}$ values $(\sim 100 \mathrm{MPa})$ together indicated a plastic deformation-dominating compaction behavior of these EPLs. Therefore, the intrinsic excellent plastic deformability of parent EPL could be the major reason why both the spray drying process and the adding of $\mathrm{NH}_{4} \mathrm{HCO}_{3}$ during spray drying had no marked influences on the compaction mechanism. On the other hand, the total evaporation of $\mathrm{NH}_{4} \mathrm{HCO}_{3}$ during spray drying, which ensured the same chemical composition of all the EPLs, is also a contributor. The intercept of the extrapolated linear region of the Heckel plot, A, is a function of the original compact volume. For materials that readily undergo plastic deformation under pressure, the value of $\mathrm{A}$ is inversely related to the final compact porosity, which is exactly the case observed in this study (Fig. 6 and Table 2).

In Table 2, PuL refers to the porosity of tablets compacted under the compaction force of $4.5 \mathrm{kN}$. Results showed that the porosities of the spray dried EPLs tablets were similar and were all higher than that of parent EPL tablets. In addition, compared to parent EPL, spray-dried porous EPLs underwent more significant volume reduction during tableting and thus, showed greater elastic recovery during unloading (Table 2). However, the effect of the increased elastic recovery on tablet TS was totally overcome by the increased interparticle and intraparticle bonding forces, both of which were induced by increased feed porosity. Therefore, the increased fast elastic stretch was not a big concern in this study in terms of tablet TS. Conversely, it could be a positive behavior to increase the porosity of tablets finally formed for boosting the drug dissolution after oral administration.

\subsection{Tablet dissolution}

Dissolution rate is quite important in the application of tablets; it directly determines the bioavailability of drugs. For insoluble drugs, the slow dissolution rate is the first problem needed to be solved. In this experiment, it was found that the dissolution of parent EPL tablets was slow (>60 min for total dissolution). As a TCM extract, EPL is multicomponent in nature; the dissolution behaviors of a total of 11 peaks in the characteristic fingerprint spectrum of EPL (Fig. 7) rather than only the active component, puerarin (the highest peak 4), were investigated. The results are shown in Fig. 8, from which the following points were concluded. First, the spray drying process itself significantly increased by $\sim 2$-fold the dissolution rate of all 11 peaks, and their dissolution was nearly completed within $20 \mathrm{~min}$ (Fig. 8B). The $f_{2}$ values of the 11 dissolution profiles between Fig. 8A and B were 22-29, which demonstrated that there were

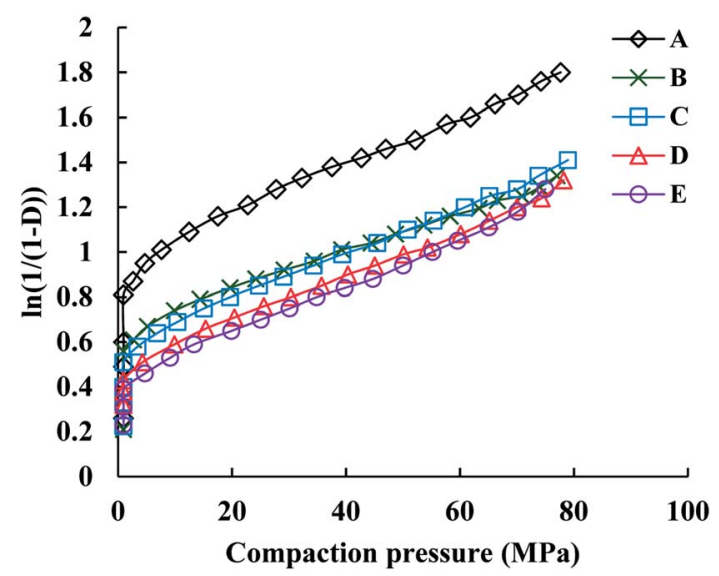

Fig. 6 Heckel profiles of parent and various other spray-dried EPLs. ((A) Parent EPL; (B) EPL spray dried without $\mathrm{NH}_{4} \mathrm{HCO}_{3}$; (C) EPL spray dried with $6.67 \% \quad \mathrm{NH}_{4} \mathrm{HCO}_{3}$; (D) $\mathrm{EPL}$ spray dried with $10.00 \%$ $\mathrm{NH}_{4} \mathrm{HCO}_{3}$; (E) EPL spray dried with $13.33 \% \mathrm{NH}_{4} \mathrm{HCO}_{3}$ ). 


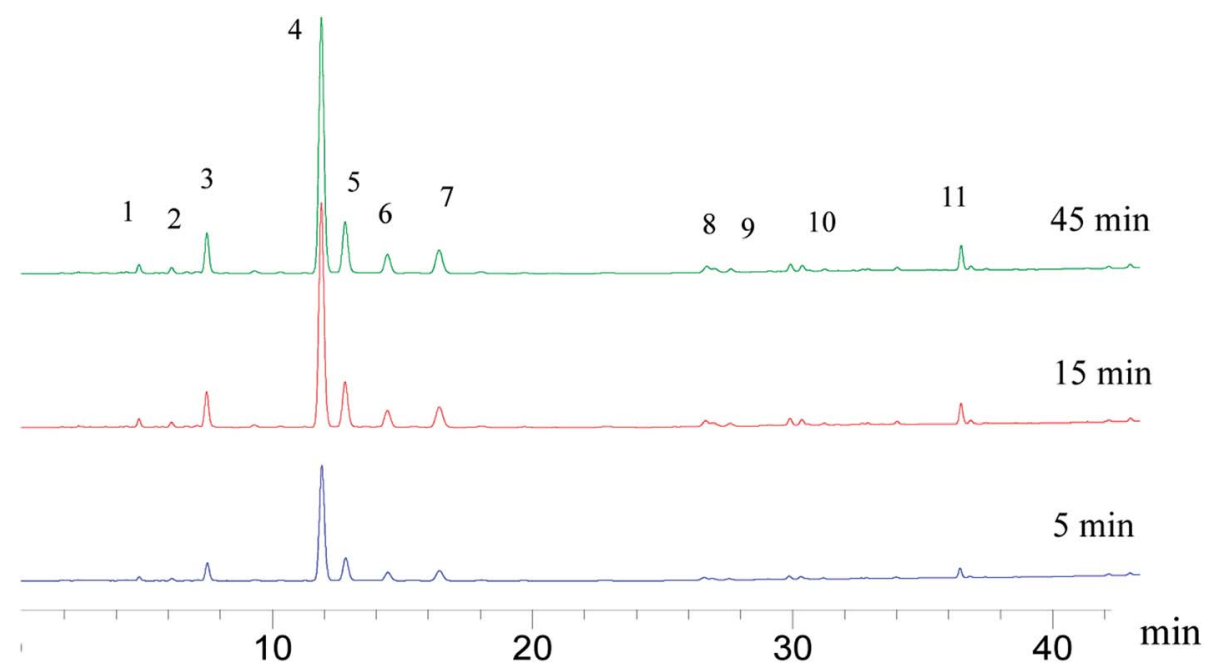

Fig. $7 \mathrm{HPLC}$ fingerprints of the EPL tablets spray dried without $\mathrm{NH}_{4} \mathrm{HCO}_{3}$ at different dissolution times (peak 4, puerarin).
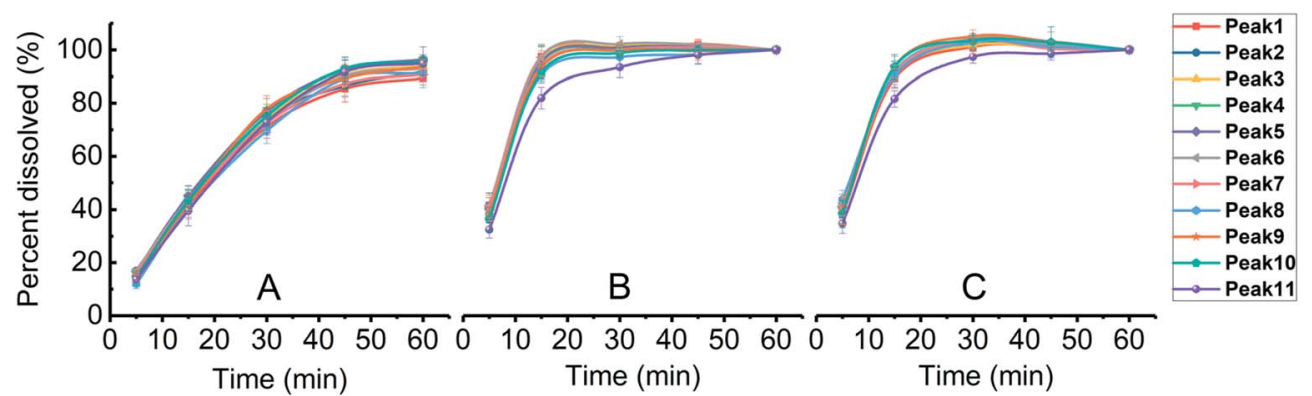

Fig. 8 Percent dissolved versus time plots of characteristic peaks for various EPL tablets. (A) Parent EPL; (B) EPL spray dried without $\mathrm{NH}_{4} \mathrm{HCO}_{3}$; (C) EPL spray dried with $10.00 \% \mathrm{NH}_{4} \mathrm{HCO}_{3}$ (mean $\pm \mathrm{SD}, n=3$ ).

significant differences between parent and fabricated EPL tablets. In terms of the unchanged XRD and $P_{\mathrm{y}}$, there should be no marked changes in solid state and physical status of EPL components. Therefore, the improvement should mainly be caused by the remarkable increase in tablet porosity (Fig. 2, 6 and Table 2). ${ }^{20}$ Second, no further significant improvement in dissolution was observed with the further increase of tablet porosity by co-spray drying EPL with $\mathrm{NH}_{4} \mathrm{HCO}_{3}$ (Fig. 8C). The $f_{2}$ values of the 11 dissolution profiles between Fig. $8 \mathrm{~B}$ and $\mathrm{C}$ were 70-93, demonstrating that there was no significant difference between fabricated EPL tablets. This could be attributed to both the relatively limited further increase in tablet porosity (Fig. 2, 6 and Table 2) and the already quite fast dissolution achieved by the spray drying process itself (total dissolution within $\sim 20$ $\mathrm{min}$ ). Third, the nearly synchronous release of the 11 peaks was observed for all three EPL tablets studied. When a dissolution improvement strategy is being developed for a multicomponent TCM, it is important to ensure that a synchronous increase is achieved for all the components. TCM generally exerts its action by means of holistic synergistic effects of multiple components; ${ }^{39}$ therefore, a synchronous increase in dissolution could cause a change in the composition of TCM in the blood, thus influencing its therapeutic effects and/or side effects. ${ }^{40}$ In this study, the dissolution improvement was achieved by increasing the tablet porosity, which provided an equal chance for all the components of EPL, and thus resulted in a synchronous increase in their dissolution. For porous tablets, high porosity with large surface area can facilitate water infiltration into the tablets and thus enhance its wettability and increase the contact area between drug and dissolution media, ${ }^{41}$ resulting in fast dissolution. ${ }^{13,42}$ Lastly, peak 11 showed a slightly slow dissolution behavior compared to the others (Fig. 8B and C), which was believed to be related to its low polarity. The reverse chromatography method was used in this study, so the longer the retention time, the lower the polarity of the substance. This should not be a big concern for the actual application of porous EPL tablets developed here in terms of the relatively small content of the peak 11 in EPL (Fig. 8), the fast dissolution itself, and the essentially slight difference observed, which may be negligible in actual application. Clinically, EPL is often used for treating acute diseases such as diarrhea, acute dysentery, and cardiovascular diseases, all of which need the drug to exert its action as quickly as possible. Therefore, the significant improvement in the dissolution of porous EPL tablets is greatly beneficial to its efficacy.

\section{Conclusion}

The increase in tablet hardness is often accompanied by a decrease in the drug dissolution rate. As such, it is sometimes 
troublesome to simultaneously solve the poor compactibility and slow dissolution rate for tablet product (especially a TCMbased one) when both problems are present; in this study, we accomplished this by making use of porous drug particles. Specifically, porous EPL (a TCM extract powder) was prepared by co-spray drying EPL with different amounts of $\mathrm{NH}_{4} \mathrm{HCO}_{3}$. The particle porosity was increased with the amount of $\mathrm{NH}_{4} \mathrm{HCO}_{3}$. Spray-dried EPLs exhibited a spherical and hollow structure, which caused some significant changes in the micromeritics and tableting properties of EPL. As for compactibility, the increased porosity of spray-dried EPLs led to the increase in interparticle and intraparticle bonding forces under pressure, which made the particles bond together firmly and thus resulted in a 1.80-7.03 fold increase in tablet TS. On the other hand, the increased porosity in EPL tablets facilitated water intrusion into tablets for disintegration and dissolution, resulting in an $\sim 2$-fold synchronous increase in the dissolution rate of all 11 peaks appearing in the characteristic fingerprint spectrum of EPL. As a whole, the combination of the spray drying process with the evaporation of $\mathrm{NH}_{4} \mathrm{HCO}_{3}$ could make the production of TCM particles with specific structure and porosity feasible and flexible. Porous particles can not only improve the performance of the existing tablets but can also result in the preparation of more APIs as qualified tablets. Therefore, the porosity adjustment is a very meaningful way to improve the tabletability of TCM, and it is worth further investigation.

\section{Conflicts of interest}

There are no conflicts to declare.

\section{Acknowledgements}

This work was sponsored by the National Natural Science Foundation of China (81503263), the Natural Science Foundation of Shanghai (18ZR1439800), and the Xinglin Scholar Program of Shanghai University of Traditional Chinese Medicine.

\section{References}

1 P. Shivanand and O. L. Sprockel, Powder Technol., 1992, 69, 177-184.

2 Y. C. Cao, Z. G. Liao, X. L. Liang, G. W. Zhao, L. J. Zhao, B. Ni and M. L. Zhu, Chin. Tradit. Herb. Drugs, 2013, 44, 21052111.

3 B. Kovačič, F. Vrečer and O. Planinšek, Chem. Pharm. Bull., 2011, 59, 427-433.

4 H. Takeuchi, S. Nagira, S. Tanimura, H. Yamamoto and Y. Kawashima, Chem. Pharm. Bull., 2005, 53, 487-491.

5 H. M. Yan, E. Sun, L. Cui, X. B. Jia and X. Jin, J. Pharm. Pharmacol., 2015, 67, 1207-1214.

6 Z. Li, X. Lin, L. Shen, Y. L. Hong and Y. Feng, Int. J. Pharm., 2017, 519, 272-286.

7 J. Yuan, L. Shi, W. J. Sun, J. Chen, Q. Zhou and C. C. Sun, Powder Technol., 2013, 241, 211-218.
8 X. Han, C. Ghoroi and R. Davé, Int. J. Pharm., 2013, 442, 7485.

9 J. Li, L. Zhao, X. Lin, L. Shen and Y. Feng, AAPS PharmSciTech, 2017, 18, 3105-3115.

10 J. Z. Li, F. Wu, X. Lin, L. Shen, Y. J. Wang, Y. Feng and R. Panicucci, RSC Adv., 2015, 5, 69289-69298.

11 S. Wang, J. Li, X. Lin, Y. Feng, X. Kou, S. Babu and R. Panicucci, Int. J. Pharm., 2015, 486, 370-379.

12 Q. Zhou, L. Shi, S. Chattoraj and C. C. Sun, J. Pharm. Sci., 2012, 101, 4258-4266.

13 M. Zhou, L. Shen, X. Lin, Y. Hong and Y. Feng, RSC Adv., 2017, 7, 39490-39501.

14 M. Saffari, A. Ebrahimi and T. Langrish, Eur. J. Pharm. Sci., 2016, 83, 52-61.

15 S. Sharma, P. Sher, S. Badve and A. P. Pawar, AAPS PharmSciTech, 2005, 6, E618-E625.

16 L. M. Bimbo, M. Sarparanta, H. A. Santos, A. J. Airaksinen, E. Mäkilä, T. Laaksonen, L. Peltonen, V. P. Lehto, J. Hirvonen and J. Salonen, ACS Nano, 2010, 4, 3023-3032.

17 C. Y. Huang, T. H. Huang, C. T. Kao, Y. H. Wu, W. C. Chen and M. Y. Shie, J. Endod., 2017, 43, 69-76.

18 A. Al-khattawi and A. R. Mohammed, Expert Opin. Drug Delivery, 2013, 10, 651-663.

19 C. Gervelas, A. L. Serandour, S. Geiger, G. Grillon, P. Fritsch, C. Taulelle, B. Le Gall, H. Benech, J. R. Deverre, E. Fattal and N. Tsapis, J. Controlled Release, 2007, 118, 78-86.

20 K. I. Koizumi, Y. Watanabe, K. Morita, N. Utoguchi and M. Matsumoto, Int. J. Pharm., 1997, 152, 127-131.

21 A. Al-Khattawi, J. Koner, P. Rue, D. Kirby, Y. Perrie, A. YajabiSiahboomi and A. R. Mohammed, Eur. J. Pharm. Biopharm., 2015, 94, 1-10.

22 M. Gohel, M. Patel, A. Amin, R. Agrawal, R. Dave and N. Bariya, AAPS PharmSciTech, 2004, 5, e36.

23 R. Vehring, Pharm. Res., 2008, 25, 999-1022.

24 D. M. El-Sherif and M. A. Wheatley, J. Biomed. Mater. Res., 2003, 66A, 347-355.

25 L. Zhou, Z. Zuo and M. S. S. Chow, J. Clin. Pharmacol., 2005, 45, 1345-1359.

26 J. T. Fell and J. M. Newton, J. Pharm. Sci., 1970, 59, 688-691.

27 N. A. Armstrong and R. F. Haines-Nutt, Powder Technol., 1974, 9, 287-290.

28 S. E. Bae, J. S. Son, K. Park and D. K. Han, J. Controlled Release, 2009, 133, 37-43.

29 A. Ebrahimi, M. Saffari and T. Langrish, Powder Technol., 2015, 283, 171-177.

30 Y. Wei, Y. Wang, H. Zhang, W. Zhou and G. Ma, J. Colloid Interface Sci., 2016, 478, 46-53.

31 J. Salonen, A. M. Kaukonen, J. Hirvonen and V. P. Lehto, J. Pharm. Sci., 2008, 97, 632-653.

32 J. Vicente, J. Pinto, J. Menezes and F. Gaspar, Powder Technol., 2013, 247, 1-7.

33 L. A. Felton, Drug Dev. Ind. Pharm., 2012, 38, 1029.

34 J. Nordström and G. Alderborn, J. Pharm. Sci., 2015, 104, 2029-2039.

35 R. W. Heckel, Trans. Metall. Soc. AIME, 1961, 221, 671-675.

36 S. Tanimura, K. Tahara and H. Takeuchi, Powder Technol., 2015, 286, 444-450. 
37 A. Hassanpour and M. Ghadiri, Powder Technol., 2004, 141, 251-261.

38 J. S. Hardman and B. A. Lilley, Nature, 1970, 228, 353-355.

39 Y. Shu, Z. Liu, S. Zhao, Z. Song, D. He, M. Wang, H. Zeng, C. Lu, A. Lu and Y. Liu, Anal. Bioanal. Chem., 2017, 409, 4849-4865.
40 S. Y. Ma, L. Shen, Y. Zhai, X. Lin, Y. Feng, L. M. Xu and K. F. Ruan, Anal. Methods, 2014, 6, 2260-2269.

41 C. Wu, Z. Wang, Z. Zhi, T. Jiang, J. Zhang and S. Wang, Int. J. Pharm., 2011, 403, 162-169.

42 M. M. Mehanna, A. M. Motawaa and M. W. Samaha, J. Pharm. Sci., 2011, 100, 1805-1818. 